DOI: http://dx.doi.org/10.22484/2177-5788.2016v42n1p175-197

\title{
Tradução e adaptação na literatura infantojuvenil: $o$ gênero fábula ${ }^{1}$
}

\author{
Clarissa Rosas
}

Resumo: No presente estudo, buscamos discutir a tradução e adaptação na literatura infantojuvenil, com foco no gênero fábula, apresentando um breve estudo de caso que tem como objeto textualizações em português de uma fábula do escritor espanhol Tomás de Iriarte. A pesquisa aborda diversos conceitos na tentativa de entender os elementos que fazem com que determinadas textualizações sejam apresentadas como adaptações, enquanto que outras sejam vistas como traduções. Nesse processo, é feita uma revisão bibliográfica com vistas a definir as semelhanças e diferenças entre os conceitos de tradução e adaptação, o que se adapta e por que se adapta na literatura infantojuvenil, o que é fábula e sua inserção na literatura infantojuvenil. A partir daí, discutimos as textualizações de fábulas por meio de verso e prosa, abordando a evolução histórica do gênero e alcançando a problemática do texto-fonte em verso e texto-alvo em prosa. Por fim, apresentamos uma breve análise de textualizações em português de uma fábula de Iriarte.

Palavras-chave: Tradução. Adaptação. Literatura infantojuvenil. Fábula.

\section{Translation and adaptation in children and youth literature: the genre fable}

Abstract: In this study, we discuss translation and adaptation in children and youth literature, focusing on the genre fable. We present a short case study of Portuguese textualizations of a fable from the Spanish writer Tomás de Iriarte. The study covers several concepts in an attempt to understand which elements make certain textualizations be presented as adaptations, while others are considered translations. In the process, we do a literature review in order to identify the similarities and differences between the concepts of translation and adaptation, what is adapted in children and youth literature and why, what is a fable, and how it is inserted in children and youth literature. From there, we discuss fable textualizations using verse and prose, where we address the historical evolution of the genre, as well as bring into focus the issue of textualizing into prose a source text originally written in verse. Finally, we present a short analysis of Portuguese textualizations of an Iriarte's fable.

Keywords: Translation. Adaptation. Children and youth literature. Fable.

\footnotetext{
${ }^{1}$ Trabalho desenvolvido sob orientação da Prof. ${ }^{a}$ Dr. ${ }^{a}$ Heloísa Pezza Cintrão, que contribuiu para o surgimento e enriquecimento de muitas ideias.
} 
ROSAS, Clarissa. Tradução e adaptação na literatura infantojuvenil.

\section{Introdução}

Hoje em dia, fala-se corriqueiramente em literatura infantojuvenil, termo já consagrado pelo mercado editorial. No entanto, até determinado período da história, não havia uma literatura voltada especialmente para esse público-alvo. Segundo Lajolo e Zilberman (2007, p. 16), após a revolução industrial, uma série de fatores culminou na estabilização de um estereótipo familiar no qual há uma divisão rígida do trabalho entre seus membros, cabendo ao pai a sustentação da família e à mãe, o cuidado da vida doméstica organização que acabou por beneficiar a criança. A partir desse momento, a preservação da infância passou a ocupar um lugar de certo prestígio social, o que motivou o surgimento de objetos industrializados, como brinquedos, e culturais, como livros infantis, além de ramos específicos nas ciências, como a psicologia infantil, a pedagogia e a pediatria.

Partindo desse contexto e em concordância com o que foi discutido por Mundt (2008), entendemos como literatura infantojuvenil aquela que foi escrita para crianças e jovens, publicada com foco nesse público-alvo ou lida por ele, situando esse conceito historicamente. Nesse sentido, é importante lembrar que estamos falando de uma literatura produzida por adultos e comprada geralmente por adultos, os quais funcionam como um público intermediário entre os textos e seus leitores finais. Os adultos, portanto, são em geral responsáveis por decidir o que a criança e o jovem gostariam de ler, o que seria adequado para eles e qual seria sua capacidade de leitura.

Neste artigo, trataremos de tradução e adaptação na literatura infantojuvenil, abordando as diferenças e aproximações entre os dois conceitos e considerando o mercado editorial brasileiro. Em seguida, fecharemos o foco no gênero fábula, discutindo sua inserção na literatura infantojuvenil e sua textualização em verso ou em prosa, apresentando por fim um estudo de caso. Para tanto, analisaremos brevemente três retextualizações em português de uma fábula do escritor espanhol Tomás de Iriarte, para entender em que medida o texto foi adaptado em cada caso, levantando hipóteses sobre os possíveis propósitos de tais textualizações. 
ROSAS, Clarissa. Tradução e adaptação na literatura infantojuvenil.

\section{Tradução e adaptação}

Quando se trata de literatura infantojuvenil, o mercado editorial brasileiro comumente se refere a histórias adaptadas ou, até mesmo, recontadas. Esses termos podem se referir a histórias traduzidas inter ou intralinguisticamente: no primeiro caso, dizem respeito à literatura infantojuvenil traduzida de um idioma a outro; no segundo caso, geralmente representam a literatura canônica nacional transformada em textos considerados acessíveis para o público infantojuvenil. Aqui, pretendemos tratar unicamente da tradução interlinguística. Dado que esta é sempre uma forma de recontar algo em outro idioma, reconstruindo e adaptando o texto a especificidades linguísticas ou culturais (a depender do propósito da tradução e do públicoalvo), os atos de recontar e adaptar podem ser vistos como muito próximos da tradução propriamente dita. A questão que se coloca, portanto, é: em que medida uma tradução se diferencia de uma adaptação?

Vinay e Darbelnet (1958) definem adaptação como um procedimento técnico de tradução, no qual um segmento textual traduzido estabelece uma relação parcial de equivalência com o segmento de origem, ocorrendo uma assimilação cultural em que uma noção característica da cultura-fonte é traduzida por uma noção semelhante específica da cultura-alvo. Esse procedimento representaria a maior distância possível do texto-fonte, em oposição ao empréstimo (em que um segmento do texto-fonte é reproduzido no texto-alvo, com ou sem marcadores específicos como aspas, itálico ou negrito), procedimento que mais aproximaria os textos fonte e alvo. Nesse caso, a adaptação é vista como um procedimento técnico, que em maior ou menor medida pode fazer parte de qualquer texto traduzido.

Bastin (1998) afirma que o termo adaptação abarca noções vagas como imitação e reescritura, entre outras, e que consiste em algumas operações tradutórias que resultam em um texto cujo vínculo com o texto-fonte é reconhecido, mas ainda assim não é percebido como uma tradução. Segundo o autor, o conceito de adaptação se constrói em sua oposição à tradução, que para tanto precisa ser vista como não-adaptação. Nesse caso, a adaptação é considerada um texto-alvo que não é uma tradução do texto-fonte, embora mantenha suas raízes nele. 
ROSAS, Clarissa. Tradução e adaptação na literatura infantojuvenil.

Ainda podemos mencionar Hutcheon (2006) e Sanders (2006) que buscam se desvencilhar da noção de fidelidade e da pretensão de que adaptadores procuram simplesmente reproduzir o texto adaptado, afirmando que adaptação é repetição, mas repetição sem réplica. A autora diz que adaptação pode ser descrita como 1) uma transposição assumida de um outro trabalho que pode ser reconhecido; 2) um ato criativo e interpretativo de apropriação; e 3) um engajamento intertextual estendido com o trabalho adaptado.

Sanders (2006) afirma que uma adaptação geralmente contém omissões, reescrituras, adições, mas ainda assim pode ser reconhecida como o trabalho de determinado autor, o que coincide com a primeira definição de Hutcheon. Em contrapartida, faz um contraste entre adaptação e apropriação, definindo esta como um texto que, embora mantenha certas características do texto de partida, afasta-se o suficiente para que este não mais seja reconhecido - o que vai de encontro à segunda definição de Hutcheon.

Milton (2013) ressalta que a terminologia da área é extremamente confusa, incluindo uma série de termos como os já citados adaptação e apropriação, e outros como recontextualização, redução, simplificação e condensação. A adaptação é apontada em circunstâncias tais como literatura traduzida para crianças, adaptações intersemióticas, publicidade, adaptações por necessidades especiais, adaptações por necessidades fonéticas (como em óperas), censuras e melhorias do texto, questões políticas, adaptações de literatura clássica para mercado de massa, localização de sites e jogos - e tudo isso varia historicamente.

Tendo em vista que os Estudos da Tradução ainda não parecem tratar dessas classificações de forma unívoca, para a presente discussão iniciaremos tratando como adaptações os textos que não reconhecemos como traduções, quer seja porque as próprias editoras os definem como tal, quer seja porque percebemos entre os textos-fonte e alvo diferenças formais relevantes, como a mudança de verso para prosa. E, para a análise das fábulas traduzidas (ou adaptadas), levaremos em conta um breve levantamento do que se adapta e por que se adapta, que será discutido a seguir. 
ROSAS, Clarissa. Tradução e adaptação na literatura infantojuvenil.

\section{O que se adapta e por que se adapta}

Como a literatura infantojuvenil é geralmente produzida por adultos, os textos-alvo passam por uma espécie de filtro: as pessoas envolvidas em sua produção julgam o que é ou não adequado para seu público-alvo, o que costuma acarretar em procedimentos que, em maior ou menor medida, adaptam o texto-alvo ao propósito estabelecido. Em geral, os segmentos considerados problemáticos são títulos e nomes próprios, alimentos, fenômenos temporais, elementos da fauna e da flora, lugares e referências históricas, culturais ou literárias, costumes e hábitos, trocadilhos, expressões idiomáticas, onomatopeias, ilustrações, socioletos e dialetos, entre outros.

Conforme discussão apresentada por Mundt (2008), essas adaptações podem ser necessárias, tornando acessíveis à criança ou ao jovem aspectos que se apresentariam como obstáculos à leitura, já que é mais fácil partir do conhecido (ou dado) para chegar ao desconhecido (ou novo). Todavia, algumas adaptações podem também implicar uma visão da criança e do jovem como leitores incapazes, com soluções tradutórias que achatam o texto em clichês e estereótipos, abrindo mão de acrescentar novas informações a esse público-alvo, aumentando, assim, o peso do dado. De acordo com Beaugrande e Dressler (1983), a informatividade, que estabelece essa relação entre o dado e o novo, é um dos fatores responsáveis pela textualidade de qualquer texto bem constituído, mas se faz necessário notar que seu equilíbrio é algo muito subjetivo.

Bunn (2011), em artigo que apresenta sua experiência na tradução de onze livros de literatura infantojuvenil, relata que, no geral, adaptaram-se elementos lexicais buscando escolhas ponderadas, privilegiou-se a ordem direta da maioria das frases e segmentaram-se períodos muito longos. Além disso, segundo a autora, "evitou-se nas traduções o uso excessivo de pronomes oblíquos e as escolhas lexicais que geravam aliteração ou eco" (105). As falas dos personagens receberam um tom mais coloquial e a do narrador, um mais formal, "optando, por exemplo, pela forma contraída pra quando as falas eram dos personagens e para quando eram do narrador" (p. 105). Tendo em vista essa experiência, consideramos que as escolhas lexicais, a ordem e o tamanho das orações, o uso de pronomes oblíquos e os níveis de coloquialidade podem ser aspectos interessantes para observar durante a análise. 
ROSAS, Clarissa. Tradução e adaptação na literatura infantojuvenil.

Outro aspecto que parece ser relevante quando se discute a adaptação de literatura infantojuvenil é o enredo em si, por vezes julgado como inadequado para o público-alvo. É comum observar em contos de fadas, por exemplo, a adaptação do enredo de modo a poupar os personagens de grandes sofrimentos. A Sereiazinha ou Pequena sereia, de Hans Christian Andersen, sentia-se como se facas atravessassem seus pés a cada passada, e seu fim é transformar-se em espuma do mar após a morte. Essa, no entanto, não é a versão mais conhecida da história, muito mais benévola com a ex-sereia, que recebe até um final feliz - tão profusamente difundido na literatura voltada para esse público.

Entendendo melhor o que se adapta e por que se adapta, podemos fechar o foco no gênero que pretendemos analisar: a fábula. Para começar, discutiremos a definição do gênero e, em seguida, sua inserção na literatura infantojuvenil.

\section{O que é fábula?}

A palavra fábula tem origem latina e, segundo Coelho (1984), tem sido usada no sentido de relato, conversação ou narração alegórica. Advém do verbo fabulare (falar) e é uma das mais antigas formas de narrativa da tradição oral, podendo ser construída em verso ou em prosa - o que, como veremos, varia ao longo do tempo. Sua origem é controversa, mas possivelmente remonta à Índia antiga. Conta-se que o primeiro fabulário foi o Pañcatantra, redigido em sânscrito por volta do século VI a.C. (LACERDA, 1993, p. 10). Um rei teria encomendado o material a um sábio para que os príncipes seus filhos fossem instruídos, já que considerava preferível um filho morto ou não-nascido a um filho estúpido. "Desde então, [...] circula pelo mundo com o propósito de educação dos jovens", declara a abertura do fabulário (PAÑCATANTRA, 2004, p. 25).

De acordo com Bunn (2008), algumas correntes históricas atribuem a origem ocidental das fábulas ao grego Esopo, também por volta do século VI a.C., sendo Fedro, fabulista romano do século I a.C., o responsável por enriquecê-las estilisticamente. Muitos acreditam que as fábulas tenham nascido bem antes, no século XVIII a.C., na Suméria. Por seu lado, Esteban (1981), na introdução do volume Calila y Dymna, coleção hindu de contos de animais 
ROSAS, Clarissa. Tradução e adaptação na literatura infantojuvenil.

provavelmente compilada por um brâmane a partir da tradição oral, afirma que na história da literatura universal é possível rastrear uma linha de continuidade que parte da Caxemira - região no norte indiano disputada pela Índia e pelo Paquistão - há mais de 2.500 anos, e se estende lentamente até o ocidente, chegando a La Fontaine, fabulista francês do século XVII, e Samaniego, fabulista espanhol do século XVIII.

As fábulas são narrativas de natureza simbólica que têm como propósito fundamental enunciar uma lição de moral e, por via de regra, dividem-se em duas partes: uma história, que expõe uma situação vivida, geralmente, por animais; e sua sentença moral, que é o significado dessa história. Em sua linguagem predomina o diálogo, quer seja direto ou indireto: segundo Portella (1983, p. 131), “é através da conversa entre duas pessoas que se manifestam as divergências, os conflitos, os atritos, matéria prima para a narrativa fabular". Então, nesse gênero, os personagens animais ganham voz e são atribuídos de características do comportamento humano, representando estereótipos como trabalhador, preguiçoso, vaidoso, corajoso, egoísta, mentiroso, ingênuo, etc. Aproxima-se, assim, da sátira menipeia descrita por Frye (1975, p. 304), a qual trata de atitudes espirituais e não de pessoas em sua complexidade psicológica. $\mathrm{Na}$ composição de personagens, esse gênero recorre a "profissionais de todos os tipos, pedantes, fanáticos, excêntricos, adventícios, virtuosos, entusiastas, rapaces e incompetentes” (p. 304), que são tratados de acordo com sua relação profissional com a vida, deixando à parte seu comportamento social. Desse modo, a sátira menipeia apresenta as pessoas como porta-vozes das ideias que representam, o que acontece de forma similar nas fábulas, nas quais são os animais que representam ideias ou atitudes.

De acordo com Lacerda (1993, p. 9),

[...] dar classificação exata ao gênero literário conhecido como "fábula" é praticamente impossível. Sendo uma das formas de narrativa mais recuada no tempo, confunde-se com a mitologia, é irmã gêmea do apólogo, aproxima-se do conto popular, introduz-se na região da lenda e do folclore, e acaba por se tornar um pouco de tudo isso. Em sua versão mais pura, se assim se pode dizer, conserva-se, entretanto, uma pequena história, muito simples, na qual as personagens são animais, e cujo remate, invariavelmente, tem intenções moralizantes. 
ROSAS, Clarissa. Tradução e adaptação na literatura infantojuvenil.

Segundo Moisés (2004), ainda que a fábula se aproxime do apólogo e da parábola, a distinção entre essas narrativas curtas e marcadas pelo conteúdo moral residiria nos personagens: quando protagonizada por objetos inanimados, seria o apólogo; por seres humanos, a parábola; e por animais irracionais, a fábula. Quanto aos demais gêneros mencionados por Lacerda, podemos nos apoiar na definição de ambos os autores para apontar no que diferem: para qualificar-se como fábula, espera-se que os personagens sejam animais e que haja um propósito moralizante no relato, o que de modo geral não se aplica à mitologia, ao conto popular ou de fadas, à lenda e ao folclore. Quanto à alegoria, por vezes também confundida com a fábula, é definida por Frye (1975, p. 93) como "uma abordagem 'abstrata', que começa com a ideia e depois tenta encontrar uma imagem concreta para representá-la". Segundo o autor, "temos real alegoria quando um poeta indica explicitamente a relação de suas imagens com exemplos ou preceitos, e assim tenta indicar como um comentário sobre ele deveria conduzir-se" (p. 93). A fábula, como vimos, parte de elementos concretos - os personagens - para a representação de ideias ou disposições de caráter - o abstrato. Assim, diferencia-se também da alegoria.

Voltando-nos ainda para a dimensão cultural do gênero, é possível considerar a definição de Fernandes (2001, p. 7), para quem a "fábula é um texto narrativo que registra o modo de vida dos povos". E, partindo dessa definição, podemos igualmente levantar um ponto relevante: todos os autores mencionados até agora usaram o termo 'narrativa' para conceituar a fábula. O dicionário Aulete apresenta essa palavra como sinônimo de 'narração', o que é definido por Moisés (2004, p. 314) como a ação de narrar ou relatar, enquadrando o vocábulo na arte oratória ou na prosa de ficção. Todavia, segundo o autor,

[...] em crítica literária, o termo [narração] às vezes é usado como sinônimo de história, fábula, ação, numa abusiva extensão semântica. Melhor será fixar o vocábulo "narrativa" para a denominação genérica, e reservar o vocábulo "narração" como designativo de recurso expressivo da poesia épica tradicional [...] ou da prosa de ficção, lado a lado com a descrição, o diálogo e a dissertação ou comentário. (MOISÉS, 2004, p. 314) 
ROSAS, Clarissa. Tradução e adaptação na literatura infantojuvenil.

Assim, chegamos a uma definição genérica de fábula como narrativa, em companhia de história e ação, com a presença obrigatória de personagens e diálogos, quer sejam diretos ou indiretos. Acrescentamos a essa definição uma tendência que parece ser comum ao gênero: a de que a narrativa se desenvolva em uma única cena. Geralmente, não há ontem ou amanhã, não há dois ou mais cenários, apenas uma situação que transcorre em um cenário único e tem começo, meio e fim em uma só cena. Em conjunto com a extensão do texto, essa tendência justificaria, por exemplo, o porquê de não considerarmos “A revolução dos bichos", de Orwell, como uma fábula. Esteban (1981), por seu lado, aponta que o tempo da ação nesse gênero segue seu curso normal, se acelera, se detém ou se condensa em função das necessidades do narrador, podendo abarcar um período de vários anos ou mal chegando a compreender o tempo de diálogo dos personagens.

Toda essa conceituação da fábula um pouco fronteiriça, parecendo por vezes se superpor a outros gêneros ou ter um uso mais amplo e outro mais restrito, pode ser explicada pelo caráter mutável e um pouco difuso do que se chama gênero textual, à luz das definições de Bakhtin (2000) e Marcuschi (2005; 2008). Segundo este,

[...] usamos a expressão gênero textual como uma noção propositalmente vaga para referir os textos materializados que encontramos em nossa vida diária e que apresentam características sócio-comunicativas definidas por conteúdos, propriedades funcionais, estilo e composição característica. (MARCUSCHI, 2005, p. 22-23)

Assim, entendemos que os gêneros textuais não são estruturas estáticas e definidas de forma definitiva. De acordo com Bakhtin (2000), os gêneros são conjuntos de enunciados relativamente estáveis elaborados pelas diversas esferas da atividade humana e que apresentam uma série de semelhanças, as quais fazem com que componham um grupo identificado como uma família. Com isso, reconhecemos que a possibilidade de um caráter híbrido é uma característica intrínseca dos gêneros textuais, que são estruturas mais ou menos fixas, mas não engessadas.

Isto posto, podemos passar ao próximo ponto: afinal, fábula é mesmo literatura infantojuvenil? 
ROSAS, Clarissa. Tradução e adaptação na literatura infantojuvenil.

\section{A inserção da fábula na literatura infanto-juvenil}

Em geral, tem-se como dado que as fábulas constituem um gênero textual essencialmente voltado para o público infantil. Contudo, há pesquisas que demonstram que, embora atualmente sejam consideradas como literatura infantojuvenil, nem sempre as fábulas foram pensadas especialmente para crianças e jovens. Cavalcanti (2007), por exemplo, aponta que as fábulas não são por essência infantis e educativas, mas podem sê-lo se for este o propósito de quem as utiliza. Também segundo Fernandes (2001), originalmente a fábula não constituía um gênero para crianças e somente mais tarde escritores como La Fontaine, no século XVII, e Monteiro Lobato, no século XX, escreveram fábulas voltadas notadamente para o público infantil.

Todavia, é importante lembrar que as concepções sobre a infância variam historicamente, conforme apontam Philippe Ariès (1981) e Lajolo e Zilberman (2007). Como explanado na introdução, até fins do século XVIII a criança era vista como um adulto em escala reduzida e não se dava muita atenção às particularidades de cada período da vida humana, o que constitui um ambiente pouco favorável ao desenvolvimento de uma literatura infantil. Isso não significa, no entanto, que as fábulas não fossem produzidas pensando na educação de pessoas em formação, as quais são, em geral, jovens - como vimos no caso do Pañcatantra, que é justamente uma das possíveis origens da fábula.

Segundo Lajolo e Zilberman (2007, p. 59), quando surgiu na Europa moderna, a literatura infantil adotou como tema preferencialmente motivos rurais, aproveitando narrativas folclóricas, contos de fadas de origem camponesa, fábulas e outros relatos similares. Assim, chegamos a um ponto que nos interessa: ainda que a princípio as fábulas não tenham sido especificamente direcionadas ao público infantil, a mudança de condição da criança na sociedade deu espaço ao desenvolvimento de uma literatura infantil que se apropriou desse gênero.

É relevante ainda mencionar que, conforme pesquisa recente (desenvolvida em artigo intitulado "Uma contribuição para a historiografia da tradução de fábulas para o português: o caso de Tomás de Iriarte", desta autora, no prelo), hoje em dia o público-alvo das fábulas no 
ROSAS, Clarissa. Tradução e adaptação na literatura infantojuvenil.

Brasil é marcadamente o infantojuvenil: na citada pesquisa foi realizado um levantamento bibliográfico no acervo da Fundação Biblioteca Nacional para investigar quais autores de fábulas têm/tiveram espaço no mercado editorial brasileiro, desde quando circulam fábulas traduzidas no Brasil e quem é o público-alvo das traduções. No levantamento, foram verificados determinados indicadores de público-alvo, de modo a esquematizar essas informações. Os resultados da pesquisa apontam a prevalência da criança e do adolescente como público-alvo atual das fábulas no Brasil.

Assim, passamos para a discussão das textualizações de fábulas por meio de verso e de prosa, abordando a evolução histórica do gênero e alcançando a problemática do texto-fonte em verso e texto-alvo em prosa, para em seguida analisar três retextualizações de uma fábula de Iriarte em português.

\section{Fábulas em verso e prosa}

A linguagem poética foi durante muito tempo o modo de expressão literário por excelência, portanto era frequente que a produção literária ocorresse em verso: até os tempos modernos, todos os gêneros nobres (e às vezes até os menos nobres, como receitas) eram escritos em verso, conforme aponta Candido (1993). As fábulas mesmo, de acordo com Moisés (2004), eram escritas em verso até o século XVIII, quando passaram a adotar prioritariamente a prosa como veículo de expressão. Isso implica que quando a literatura infantil começou a ser produzida ela era, substancialmente, em versos.

Quanto ao uso de verso e rima, é comum a associação com a poesia. A esse respeito, Candido (1993, p. 13) aponta que "a poesia não se confunde necessariamente com o verso, muito menos com o verso metrificado. Pode haver poesia em prosa e poesia em verso livre". Assim, o autor conclui que pode ser feita em verso muita coisa que não é poesia e que, não obstante sejam impraticáveis julgamentos retrospectivos nesse sentido, o fato é que a percepção de cada leitor faz com que determinado texto seja lido como poesia ou não. A poesia didática do século XVIII, por exemplo, embora perfeitamente metrificada e em sua origem uma atividade poética legítima, parece hoje mais próxima dos valores da prosa. A ideia de "percepção do leitor" parece fazer todo 
ROSAS, Clarissa. Tradução e adaptação na literatura infantojuvenil.

o sentido nesse caso: Arrojo (2007) exemplifica bem essa questão, ao descrever formas diferentes de perceber um mesmo texto, quer seja apresentado ao leitor como um bilhete deixado sem maiores pretensões, quer seja apresentado como um poema de um autor conhecido.

Sendo a estruturação em versos indiferente à poesia, as fábulas em verso poderiam, então, ser consideradas como prosa? Segundo Moisés (2004, p. 71), "tanto da poesia como da prosa ficam excluídas as manifestações híbridas ou paraliterárias como o teatro, a poesia didática, o jornalismo, a oratória, o apólogo, a fábula, a crônica, etc". O autor entende a fábula, portanto, como uma manifestação híbrida, concordando com Portella (1983, p. 119-120), para quem "o hibridismo da fábula não se restringe à forma mas também ao conteúdo".

Esteban (1981, p. 24) diz que nesse gênero as descrições se resumem a pinceladas e detalhes que enquadram o comportamento e a ação dos personagens, desde que sejam relevantes para a ação narrada; e Portella (1983, p. 133) aponta que na fábula não se usam descrições, por tratar-se de um gênero de caráter eminentemente objetivo - como também destaca Lessing (apud Portella, 1983, p. 133), ao defender que descrições são "embelezamentos supérfluos que desviam a atenção do leitor da finalidade da fábula e impedem de tornar-me consciente de uma verdade moral". As ideias dos autores citados talvez pareçam descabidas, pois está claro que descrições podem ser perfeitamente objetivas e relevantes, mas entendemos aqui que essas considerações ressaltam uma característica importante das fábulas: quem as escreve costuma dedicar muito mais tempo à ação que ao ambiente onde essa ação se desenrola ou à enumeração minuciosa de detalhes. Assim como acontece com o conto ${ }^{2}$, que é muito mais conciso e focado na ação que o romance.

\footnotetext{
${ }^{2}$ Aqui nos referimos à ideia de conto pós-Edgar Allan Poe, e não aos contos de fadas ou contos populares. Grosso modo, o gênero conto caracteriza-se por características como brevidade e objetividade, com economia dos meios narrativos, o que já foi profusamente teorizado por autores como Edgar Allan Poe (1999), Julio Cortázar (2006), Nádia Gotlib (2006) e Ricardo Piglia (2004).
} 
Desse modo,

[...] na fábula todas as palavras são medidas e direcionadas para um alvo bem definido. Mesmo sendo constituída de imagens e linguagem figurada, não cai jamais no vazio. Pelo contrário, porque a fábula deve relacionar-se com a vida, porque ela deve executar a verossimilhança entre a vida e a realidade, também será real, plástica, objetiva. As imagens empregadas devem do mesmo modo ser de fácil percepção para que o leitor possa realizar a verossimilhança entre a fábula e a própria vida, tirando dela o proveito em forma de padrão de comportamento. A fábula, na concepção de seus criadores, tem finalidade didascálica e, assim sendo, a linguagem em que é vazada deve ser eminentemente didática, simples, objetiva. (PORTELLA, 1983, p. 131)

Essa ausência (ou presença mínima) de descrições que se justifica na concisão e no foco no comportamento - portanto, ação - da fábula, aliada ao caráter didático que exige a escolha de palavras e imagens de fácil percepção para atingir sua finalidade moralizante, fazem com que a fábula se afaste da essência incomunicável da poesia, tão ligada à percepção individual e à experiência pessoal. $\mathrm{O}$ estranhamento poético, na fábula, provocaria um desvio de foco, uma distração ao propósito definido.

Podemos ainda abordar, neste momento, a questão das rimas, geralmente utilizadas nas fábulas em verso. A questão básica a ser levantada, nesse sentido, diz respeito ao que a rima pode provocar como sensação e de que modo afeta a maneira de significar do texto. Tendo em vista o cenário apresentado, acreditamos que, de modo geral, a presença de rimas em fábulas está relacionada a uma necessidade de enquadrar os textos nos conformes dos padrões literários pregressos, que exigiam a escritura em verso, não contribuindo particularmente para a construção imagética dos textos. Nesse caso, o fato de que ocasionalmente ainda se escrevam ou traduzam fábulas em verso rimadas e metrificadas se justificaria na manutenção de uma tradição literária.

Ainda, é importante mencionar o potencial mnemônico do verso rimado. De acordo com Spina (2002, p. 89),

[...] a estrutura rímica da frase sempre foi um poderoso auxiliar da memória. É por isso que as sentenças morais, os provérbios, as máximas de objetivo didático, foram modelados numa forma rímica, para efeito de conservação. A rima era, pois, o recurso predominante para marcar os hemistíquios da expressão paremiológica. 
ROSAS, Clarissa. Tradução e adaptação na literatura infantojuvenil.

Dado o caráter oral das fábulas, que eram contadas sem o auxílio de um suporte físico até que alguém as compilasse, o verso rimado era um facilitador: possivelmente, esse era um dos fatores que contribuíam para que fossem produzidas em verso, não em prosa. Com o tempo, surgiram fabulários de diversos autores, registrando em papel fábulas que circulavam oralmente até então. A partir daí, percebe-se que as fábulas assumiram mais frequentemente a forma de prosa, em especial quando voltadas para o público infantojuvenil - a pesquisa mencionada na seção IV apontou uma tendência maior a traduzir-se para o público adulto apenas fábulas gregas e latinas, o que nos leva a supor uma relação com o estudo das letras clássicas, possivelmente mantendo a estrutura versificada tal qual os textos gregos e latinos de Esopo e Fedro. Essa hipótese, contudo, ainda está sendo investigada.

\section{Analisando textualizações de uma fábula de Iriarte}

As fábulas de Iriarte - publicadas pela primeira vez em 1782 pela Imprenta Real em Madri e, segundo seu editor (IRIARTE, 1782, prólogo), as primeiras inteiramente originais em castelhano - foram traduzidas em diversos momentos para o português, tanto brasileiro quanto

europeu. É digno de nota que uma tradução não ocorre sem um propósito e um público-alvo definidos e que há diversos fatores que constituem as condições de produção dessa retextualização.

Observando fábulas traduzidas, recontadas ou adaptadas que circulam no mercado editorial brasileiro, percebemos que é prática comum ter como resultado textos em prosa, ainda que as fábulas mais frequentemente traduzidas tenham sido escritas em verso. Dentre os autores traduzidos, destacam-se Esopo e La Fontaine, de acordo com o levantamento bibliográfico já mencionado ("Uma contribuição para a historiografia da tradução de fábulas para o português: o caso de Tomás de Iriarte", desta autora, no prelo). A hipótese que se coloca aqui é que as traduções tenham se adequado às mudanças formais do gênero ao longo do tempo, conforme apontado anteriormente em citação de Moisés (2004), que afirma que a partir do século XVIII as fábulas passaram a adotar a prosa como veículo de expressão, tendo sido até então escritas em verso. 
ROSAS, Clarissa. Tradução e adaptação na literatura infantojuvenil.

Essa mudança formal pode dever-se em grande medida ao fato de que as fábulas migraram da oralidade para a escrita, o que dispensa recursos mnemônicos, mas é possível também que as traduções em prosa tenham como objetivo atingir mais facilmente o público infantil. O fato é que, quer seja para um público adulto ou infantojuvenil, a fábula sempre teve um propósito didático muito definido. Sendo assim, seria compreensível que, ao recontar ou adaptar uma fábula, um tradutor buscasse torná-la mais acessível ao seu público-alvo, de modo a alcançar seu propósito moralizante com mais eficácia. Se o público-alvo em questão é o infantojuvenil, torna-se ainda mais compreensível esse tipo de estratégia, já que se trata de um conjunto de destinatários que, a princípio, ainda não amadureceu suas habilidades de leitura.

Vejamos agora como a discussão apresentada se aplica ao estudo de caso proposto. $\mathrm{O}$ quadro a seguir traz a fábula La rana y la gallina em seis textualizações, mantendo as convenções ortográficas tal qual figuram nas edições consultadas. São elas: (1) a primeira edição espanhola de 1782; (2) uma tradução portuguesa de 1796; (3) uma edição em espanhol organizada na Inglaterra em 1917; (4) uma tradução brasileira de 1993; (5) e (6) uma edição bilíngue argentina de 1948. 
ROSAS, Clarissa. Tradução e adaptação na literatura infantojuvenil.

\section{Quadro 1- Seis textualizações da fábula La rana y la gallina, de Iriarte}

\begin{tabular}{|c|c|}
\hline $\begin{array}{l}\text { (1) La Rana y la Gallina (Madri, 1782) } \\
\text { Autor: Tomás de Iriarte } \\
\text { Desde su charco una parlera rana } \\
\text { Oyó cacarear á una gallina. } \\
\text { ¡Vayal (la dijo:) no creyera, hermana. } \\
\text { Que fueras tan incómoda vecina. } \\
\text { Y con toda esa bulla ¿qué hay de nuevo? - } \\
\text { Nada, sino anunciar que pongo un huevo. - } \\
\text { ¿Un huevo solo? iY alborotas tantol - } \\
\text { Un huevo solo ; si , Señora mia. } \\
\text { ¿Te espantas de eso, cuando no me espanto } \\
\text { De oírte como graznas noche y dia? } \\
\text { Yo, porque sirvo de algo, lo publico; } \\
\text { Tú, que de nada sirves, calla el pico. }\end{array}$ & $\begin{array}{l}\text { (2) A Raã , e a Gallinha (Porto, 1796) } \\
\text { Tradutor: Romao Francisco Antonio Creyo } \\
\text { Lá do seu charco a palradora Raã } \\
\text { Ouvio cacarejar huma gallinha, } \\
\text { Apage, diz-lhe : quem pensára irmaã, } \\
\text { Que fosses taõ incommoda visinha ! } \\
\text { ¿E com toda essa bulha que ha de novo? } \\
\text { Nada mais que dizer que ponho hum ovo; } \\
\text { i Hum ovo taõ sómente I E alborotas tanto ? } \\
\text { Hum ovo taõ sómente, sim senhora. } \\
\text { ¿ Disso te espantas quando naõ me espanto } \\
\text { Ouvindo-te grasnar a toda a hora? } \\
\text { Eu por ter algum prestimo o publico, } \\
\text { Tu que de nada serves calla o bico. }\end{array}$ \\
\hline $\begin{array}{l}\text { (3) La Rana y la Gallina (Oxford, 1917) } \\
\text { Organizador: Jaime Fitzmaurice-Kelly } \\
\text { (Al que trabaja algo, puede disimulársele que } \\
\text { lo pregone; el que nada hace, debe callar.) } \\
\text { Desde su charco una parlera Rana } \\
\text { Oyó cacarear a una Gallina. } \\
\text { "Vaya (le dijo), no creyera, hermana, } \\
\text { Que fueras tan incómoda vecina. } \\
\text { Y con toda esa bulla, ¿qué hay de nuevo?" } \\
\text {-"Nada, sino anunciar que pongo un huevo." } \\
\text { - "¿Un huevo solo? iY alborotas tantol" } \\
\text { - "Un huevo solo; si, señora mia. } \\
\text { ¿Te espantas de eso, cuando no me espanto } \\
\text { De oirte cómo graznas noche y dia? } \\
\text { Yo, porque sirvo de algo, lo publico; } \\
\text { Tú, que de nada sirves, calla el pico." }\end{array}$ & $\begin{array}{l}\text { (4) A rã e a galinha (São Paulo, 1993) } \\
\text { Tradutora: Nair Lacerda } \\
\text { Certa vez uma rã, que passava a vida a coaxar em } \\
\text { altos brados à beira da lagoa onde morava, ouviu } \\
\text { o cacarejar de uma galinha que andava ali pelas } \\
\text { margens. } \\
\text { - Como és desagradável! - gritou-lhe a rã. - } \\
\text { Por que fazes tamanha gritaria? } \\
\text { - Porque pus um ovo - respondeu a galinha. } \\
\text { - E por teres posto um ovo precisas fazer esse } \\
\text { alvoroço todo? } \\
\text { - Fica sabendo que preciso - cacarejou a } \\
\text { galinha, indignada. - Eu estou contando ao } \\
\text { mundo o que fiz. E tu, que nada fazes, por que } \\
\text { estás eternamente a coaxar? } \\
\text { Perdoa-se algum barulho a quem produziu algum } \\
\text { trabalho, mas quem nada produz deve, pelo } \\
\text { menos, produzir silêncio. }\end{array}$ \\
\hline $\begin{array}{l}\text { (5) La rana y la gallina (Buenos Aires, 1948) } \\
\text { Adaptador: Augusto Cortina }\end{array}$ & $\begin{array}{l}\text { (6) A rã e a galinha (Buenos Aires, 1948) } \\
\text { Tradutor(a): desconhecido(a) }\end{array}$ \\
\hline $\begin{array}{l}\text { Doña Gallina era bastante charlatana. Y, además, } \\
\text { muy movediza y peleadora. Todo eso resultaba, } \\
\text { sin embargo, perdonable. La Gallina era también } \\
\text { útil: diariamente ponia un huevo. } \\
\text { La Rana, en cambio, no aportaba ningún } \\
\text { beneficio. iY qué criticonal Verdad es que comia } \\
\text { muchos insectos, pero, en el lodazal, eso } \\
\text { importaba poco. Cierta vez oyó, desde su turbio } \\
\text { charco, que la Gallina cacareaba. } \\
\text { - IQué incómodal - le dijo -. ¿Por qué gritas de } \\
\text { esa manera? } \\
\text { - Porque he puesto un huevo. } \\
\text { - ¿Un huevo nada más? ¿Y alborotas tanto? } \\
\text { - IUn huevo nada más, si, señora Ranal - gritó } \\
\text { destempladamente la Gallina. Estaba furiosa - } \\
\text { Yo publico lo que hago; pero usted, que nada } \\
\text { produce, ¿por qué no se calla? } \\
\text { Al que trabaja puede disculpársele que lo pregone; } \\
\text { pero quien no hace nada debe guardar silencio. }\end{array}$ & $\begin{array}{l}\text { Dona galinha, além de muito tagarela, era } \\
\text { irrequieta e brigona. Mas tudo isso se podia } \\
\text { desculpar, porque dona galinha também era útil: } \\
\text { todos os dias punha um ôvo. } \\
\text { A rã, em troca, não prestava nenhum benefício. E } \\
\text { como vivia criticandol É verdade que devorava } \\
\text { muitos insetos, mas isso pouca importância tinha } \\
\text { no charco em que vivia. Certa feita ouviu a galinha } \\
\text { que cacarejava. } \\
\text { - Como incomodas! Por que gritas dessa } \\
\text { maneira? } \\
\text { - Porque pus um ôvo. } \\
\text { - Apenas um ôvo? E tanto alvorôço por isso? } \\
\text { - Apenas um ôvo, sim, dona rã! esbravejou a } \\
\text { galinha, de furiosa que estava. Eu grito o que faço } \\
\text { mas tu nada fazes, dona rã, por que não te calas? } \\
\text { Ao que trabalha pode-se desculpar que o apregôe, } \\
\text { mas quem nada faz deve ficar quieto. }\end{array}$ \\
\hline
\end{tabular}

Fonte: a autora (2016) 
ROSAS, Clarissa. Tradução e adaptação na literatura infantojuvenil.

O texto (1) está contido na primeira edição do livro Fábulas Literárias, publicado em Madri pela Imprenta Real, no ano de 1782. O volume contém 76 fábulas em verso, mas nenhuma delas inclui as sentenças morais que acompanham as edições mais modernas (e comumente estão presentes em fábulas). O fato é que essas sentenças morais aparecem nas últimas páginas do volume, numa seção intitulada "Índice de las fábulas y de sus asuntos". Os assuntos são as tais sentenças morais, que foram mais tarde incorporadas às fábulas. Vemos que no texto (2), que corresponde à tradução para o português europeu realizada por Romao Francisco Antonio Creyo e oferecida à Ill. ${ }^{\mathrm{ma}}$ Ex. ${ }^{\mathrm{ma}} \mathrm{Sr}^{\mathrm{a}}{ }^{\mathrm{D}} \mathrm{D}$. Maria Izabel de Lencastre Cezar e Menezes, publicada na Officina de Viuva Mallen, Filhos, e Companhia, cidade do Porto, em 1796, sob o título Fabulas literarias, não aparece a sentença moral. Esse volume conta com um índice logo no início, mas os assuntos - ou seja, as sentenças morais - foram suprimidos.

O texto (3) está contido na edição em espanhol do livro Fábulas Literárias organizado por Jaime Fitzmaurice-Kelly e publicado pela Universidade de Oxford, na Inglaterra, em 1917. O volume contém as 76 fábulas em verso, antecedidas pelas sentenças morais retiradas do índice. Ao que parece, a partir daí as retextualizações das fábulas passaram a incorporar as sentenças morais: ao menos, é o que se percebe nos textos (4) e (6). O primeiro deles é a tradução para o português brasileiro realizada por Nair Lacerda para o volume Fábulas do mundo inteiro da coleção Clássicos da Infância do Círculo de Livro, publicada em 1993, que inclui fábulas de 13 autores e ainda outras de autoria desconhecida. O volume contém 4 fábulas de Iriarte sucedidas por sentenças morais. O segundo deles está contido numa edição bilíngue ${ }^{3}$ espanhol-português, publicada em Buenos Aires pela editora Codex no ano de 1948, sob o título Fábulas de Iriarte. O volume contém 4 fábulas em prosa sucedidas por sentenças morais, sem apresentar o nome de quem traduziu.

À parte essa questão das sentenças morais, percebemos de imediato as passagens de verso para prosa nos textos (4) e (6). Ainda que nenhum dos textos seja apresentado pelas

\footnotetext{
3 A tradução para o português não faz parte da publicação original — ao que parece, foi produzida em máquina de escrever e colada manualmente nas páginas correspondentes. Não consta nome do(a) tradutor(a), mas todas as páginas têm carimbado o nome Ana Adélia, que pode ser a responsável pela tradução ou apenas a dona do exemplar.
} 
ROSAS, Clarissa. Tradução e adaptação na literatura infantojuvenil.

editoras como adaptados ou recontados - Lacerda (1993) aparece como responsável pela tradução do texto (4), e o (6) não informa nada a esse respeito -, essa mudança formal desde já indica que podemos considerá-los adaptações. Ou melhor, o texto (6) é uma tradução do texto (5), que é uma adaptação intralinguística.

Entre outros aspectos que vale a pena discutir, estão as escolhas lexicais, o uso da ordem direta ou indireta, o uso de pronomes oblíquos e os níveis de coloquialidade. A bem da verdade, os três primeiros aspectos influem diretamente no último. No quadro que segue, podemos observar as formas como alguns itens lexicais foram traduzidos, e é possível perceber uma simplificação da linguagem. O uso dos pronomes oblíquos costuma ser mais frequente em espanhol que em português, mas no nosso texto de partida não ocorre em quantidade considerável. Igualmente, o uso de inversões em versos é bastante usual, mas não é o caso do nosso objeto de estudo. Assim, os níveis de coloquialidade dependem mais das escolhas lexicais, mais elevadas e $\operatorname{arcaicas}^{4}$ nos textos (1) e (2), do século XVIII, e mais atuais e acessíveis nos textos (4) e (6), do século XX; e do uso do pronome 'tu' com as concordâncias verbais corretas, que ocorre em todos os textos traduzidos e se afasta da linguagem coloquial mais frequente no Brasil (embora usado em alguns estados, na oralidade dificilmente se faz a concordância verbal correta, mais ligada à norma culta). Todavia, é importante lembrar que apenas o texto (4) é brasileiro 5 .

\footnotetext{
4 Não que na época em que foram escritos os textos essas escolhas fossem consideradas elevadas ou arcaicas, mas esta é a leitura que se faz com os olhos de hoje.

5 Portanto, não estamos comentando as traduções em relação a suas condições de produção e percepção pelo público-alvo à época em que foram produzidas, e sim levando em conta a percepção atual que temos sobre esses textos.
} 
ROSAS, Clarissa. Tradução e adaptação na literatura infantojuvenil.

Quadro 2 - Itens lexicais do texto-fonte e dos textos-alvo

\begin{tabular}{c|c|c|c}
\hline texto (1) & texto (2) & texto (4) & texto (6) \\
\hline parlera & palradora & $\begin{array}{c}\text { que passava a vida a } \\
\text { coaxar em altos } \\
\text { brados }\end{array}$ & $\emptyset$ \\
\hline vaya & apage & $\emptyset$ & gritas \\
\hline bulla & bulha & gritaria & alvoroço \\
\hline alborotas & alborotas & alvoroço & $\emptyset$ \\
\hline grasnar & grasnar & coaxar & o que faço \\
\hline sirvo de algo & ter algum préstimo & o que fiz & grito \\
\hline
\end{tabular}

Fonte: Elaborado pela autora.

As adaptações (4) e (6) estão contidas em volumes voltados para o público infantojuvenil, o que pode ser depreendido da coleção na qual o texto (4) se insere, Clássicos da Infância, e das imagens na capa e figuras no interior do livro que se abrem ao passar das páginas formando imagens tridimensionais, no caso do texto (6). Isso nos permite conjeturar que as escolhas lexicais mais simples e a estrutura dos textos em prosa têm relação com o público-alvo. O uso do pronome 'tu', por seu lado, necessitaria mais pesquisa e não será contemplado nesse momento. 
ROSAS, Clarissa. Tradução e adaptação na literatura infantojuvenil.

\section{Considerações finais}

No presente artigo, buscamos entender a tradução e adaptação na literatura infantojuvenil, abordando as diferenças e aproximações entre os dois conceitos e considerando o mercado editorial brasileiro. Em seguida, fechamos o foco no gênero fábula, discutindo sua inserção na literatura infantojuvenil e sua textualização em verso ou em prosa, apresentando por fim um breve estudo de caso. Para tanto, analisamos três retextualizações em português de uma fábula de Iriarte, com vistas a entender em que medida o texto foi adaptado em cada caso, levantando hipóteses sobre os possíveis propósitos de tais textualizações.

A análise apresentada foi breve e certamente precisa ser aprofundada, o que deve ser o próximo passo dessa pesquisa. Nossa proposta de análise futura consiste em aplicar o modelo descritivo de tradução literária desenvolvido por José Lambert e Hendrik Van Gorp (2011) em 1985, o qual se apoia na teoria dos polissistemas de Itamar Even-Zohar (1978) e Gideon Toury (1980) e permite descrever e examinar as estratégias tradutórias em diferentes aspectos; e, de forma complementar, o estudo de Gérard Genette (2009) sobre os paratextos editoriais, elementos que contribuem para a produção de sentido e orientam a recepção da obra traduzida.

O presente artigo não tem a pretensão de esgotar esse assunto, pretendendo em contrapartida unir-se aos demais estudos que abordam, com maior ou menor profundidade, o gênero fábula, sua tradução e adaptação e sua inserção na literatura infantojuvenil. Este é, também, mais um pequeno passo de uma pesquisa maior em desenvolvimento, focada na tradução de fábulas de Iriarte para o português.

\section{Referências}

ARIÈS, Philippe. História social da criança e da família. Rio de Janeiro: LTC, 1981.

ARROJO, Rosemary. Oficina de tradução: a teoria na prática. São Paulo: Ática, 2007.

BAKHTIN, Mikhail. Estética da criação verbal. São Paulo: Martins Fontes, 2000.

BASTIN, Georges. Adaptation. Tradução Mark Gregson. In: BAKER, Mona (Org.). Routledge encyclopedia of translation studies. Londres; Nova Yorque: Routledge, 1998. 
ROSAS, Clarissa. Tradução e adaptação na literatura infantojuvenil.

BEAUGRANDE, Robert-Alain de; DRESSLER, Wolfgang Ulrich. Introduction to text linguistics. Londres: Longman, 1983.

BUNN, Daniela. Adaptação na tradução de literatura infantil: entre vinhos e cogumelos. Cadernos de Literatura em Tradução, São Paulo, n. 12, p. 103-111, 2011. Disponível em:

<http://www.revistas.usp.br/clt/article/view/49534/53609>. Acesso em: 29 mar. 2016, 16:05.

BUNN, Daniela. Da história oral ao livro infantil. Revista Estação Literária, Curitiba, p. 50-57, 2008. Disponível em: <http://www.uel.br/pos/letras/EL/vagao/ EL1Art6.pdf>. Acesso em: 29 mar. 2016, 16:06. (Vagão-volume 1)

CANDIDO, Antonio. O estudo analítico do poema. São Paulo: Terceira Leitura, 1993.

CAVALCANTI, Aroldo José Albuquerque. Contra-indicada para menores: fábula é coisa de adulto. Revista Ararobá: pesquisa, ensaios e críticas literárias, Pesqueira, PE, v. 1, maio, 2007.

COELHO, Nelly Novaes. A literatura infantil: história, teoria, análise. São Paulo: Quíron, 1984.

CORTÁZAR, Julio. Valise de cronópio. São Paulo: Perspectiva, 2006.

ESTEBAN, Mario Grande. Calila y Dymna. Madri: Emiliano Escolar, 1981.

EVEN-ZOHAR, Itamar. The Position of translated literature within the literary polysystem. In: HOLMES, James; LAMBERT, José; VAN DEN BROECK, Raymond (Org.). Literature and translation: new perspectives in literary studies. Leuven: Acco, 1978.

FERNANDES, Mônica Teresinha Ottoboni Sucar. Trabalhando com os gêneros do discurso: narrar: fábula. São Paulo: FTD, 2001.

FRYE, Northrop. Anatomia da crítica. São Paulo: Cultrix, 1975.

GENETTE, Gérard. Paratextos editoriais. São Paulo: Ateliê, 2009.

GOTLIB, Nádia Battela. Teoria do conto. São Paulo: Ática, 2006.

HUTCHEON, Linda. A theory of adaptation. Londres: Routledge, 2006.

IRIARTE, Tomás de. A rã e a galinha. Tradução Nair Lacerda. In: FÁBULAS do mundo inteiro. São Paulo: Círculo de Livro, 1993. (Coleção Clássicos da Infância)

IRIARTE, Tomás de. Fábulas de Iriarte. Edição bilíngue espanhol-português. Tradução desconhecida. Buenos Aires: Editorial Codex, 1948. (Colección Escenarios)

IRIARTE, Tomás de. Fábulas literarias. Madri: Imprenta Real, 1782. Disponível em: $<$ https://books.google.com.br/books?id=NfpFAAAAcAAJ\&hl=pt$\mathrm{BR} \& \mathrm{pg}=\mathrm{PP} 7 \# \mathrm{v}=$ onepage $\& \mathrm{q} \& \mathrm{f}=$ false $>$. Acesso em: 29 mar. 2016, 21:27. 
ROSAS, Clarissa. Tradução e adaptação na literatura infantojuvenil.

IRIARTE, Tomás de. Fabulas literárias. Tradução Romão Francisco Antonio Creyo. Porto: Officina de Viuva Mallen, Filhos e Companhia, 1796. Disponível em: $<$ https://books.google.com.br/books?id=H-8AAAAAMAAJ\&hl=pt-

$\mathrm{BR} \& \mathrm{pg}=\mathrm{PR} 10 \# \mathrm{v}=$ onepage \&q\&f=false>. Acesso em: 29 mar. 2016.

IRIARTE, Tomás de. Fábulas literárias. FITZMAURICE-KELLY, Jaime (Org.). Oxford:

Universidade de Oxford, 1917. Disponível em: <https://archive.org/details/fabulasliterarias00iriarich>. Acesso em: 29 mar. 2016.

LACERDA, Nair. Fábulas do mundo inteiro. Seleção, introdução e tradução parcial Nair Lacerda. São Paulo: Círculo do Livro, 1993. (Coleção Clássicos da Infância)

LAJOLO, Marisa e ZILBERMAN, Regina. Literatura infantil brasileira: história \& histórias. São Paulo: Ática, 2007.

LAMBERT, José; VAN GORP, Hendrik. Sobre a descrição de traduções. Tradução Marie-Hélène Catherine Torres e Lincoln Paulo Fernandes. In: GUERINI, Andrea; TORRES, Marie-Hélène Catherine; COSTA, Walter Carlos (Orgs.) Literatura e tradução: textos selecionados de José Lambert. Rio de Janeiro: 7Letras, 2011.

MARCUSCHI, Luiz Antônio. Gêneros textuais: definição e funcionalidade. In: DIONÍSIO, Angela Paiva; MACHADO, Anna Rachuel; BEZERRA, Maria Auxiliadora (Org.). Gêneros textuais e ensino. 4. ed. Rio de Janeiro: Lucerna, 2005.

MARCUSCHI, Luiz Antônio. Produção textual, análise de gêneros e compreensão. São Paulo: Parábola Editorial, 2008.

MILTON, John. Adaptation. In: GAMBIER, Yves; DOORSLAER, Luc Van (Eds.). Handbook of translation studies. Amsterdã: John Benjamin, 2013.

MOISÉS, Massaud. Dicionário de termos literários. São Paulo: Cultrix, 2004.

MUNDT, Renata de Souza Dias. A adaptação na tradução de literatura infanto-juvenil: necessidade ou manipulação? In: CONGRESSO INTERNACIONAL DA ABRALIC, 11., 2008. p. 1-10. Disponível em:

$<$ http://www.abralic.org.br/eventos/cong2008/AnaisOnline/simposios/pdf/073/RENATA_MUNDT.pd f>. Acesso em: 29 mar. 2016.

PAÑCATANTRA. Tradução Maria da Graça Tesheiner, Marianne Erps Fleming e Maria Valíria A. M. Vargas. São Paulo: Humanitas, 2004.

PIGLIA, Ricardo. Teses sobre o conto. In: FORMAS breves. Tradução José Marcos Mariani de Macedo. São Paulo: Companhia das Letras, 2004.

POE, Edgar Allan. A filosofia da composição. In: POEMAS e ensaios. Tradução Oscar Mendes e Milton Amado. São Paulo: Globo, 1999. 
ROSAS, Clarissa. Tradução e adaptação na literatura infantojuvenil.

tro

PORTELLA, Oswaldo O. A fábula. Revista de Letras, Curitiba, n. 32, p. 119-138, 1983. Disponível em: <http://ojs.c3sl.ufpr.br/ojs2/index.php/letras/article/view/19338>. Acesso em: 29 mar. 2016.

SANDERS, Julie. Adaptation and appropriation. Londres: Routledge, 2006.

SPINA, Segismundo. Na madrugada das formas poéticas. Cotia: Ateliê Editorial, 2002.

TOURY, Gideon. Descriptive translation studies and beyond. Amsterdã; Filadélfia: Benjamins, 1980.

VINAY, Jean-Paul; DARBELNET, Jean. Stylistique comparée du français et de l'anglais. Paris: Didier, 1958.

Clarissa Rosas - Universidade de São Paulo - USP | São Paulo

| São Paulo. Contato: clarissa.rosas@usp.br

Artigo recebido em março de 2016 e aprovado em julho de 2016 